\title{
Puntos críticos de protección y preservación ambiental de la cuenca Mboi Caé, ciudad de Encarnación, Paraguay
}

\author{
Edith Jacqueline Velázquez Haurón \\ jevelazquez@derecho.uni.edu.py \\ https://orcid.org/ 0000-0002-1788-8013
}

María Gloria Cabrera Romero

gloria.cabrera@agr.una.py

Universidad Nacional de Itapúa

Encarnación - Paraguay

\section{RESUMEN}

El presente estudio tuvo como objetivo determinar los puntos críticos de protección y preservación ambiental de la cuenca Mboi Caé, considerando la incidencia humana que se está desarrollando en la actualidad alrededor de la misma. En el planteamiento metodológico de la investigación, fueron planteadas tres dimensiones generales de análisis: estado del agua y la cobertura boscosa, el estado del boque y el factor humano. Para la recolección de datos fueron utilizados los siguientes instrumentos: mapeo, observación y transecta, registro fotográfico, entrevistas, grupo focal con instituciones involucradas y análisis documental. Pudo verificarse la existencia de uso del suelo inapropiado y no controlado en la referida cuenca, lo que está afectando la integridad de este y de la cuenca en general, sin mencionar los efectos negativos que ejerce este factor sobre las poblaciones cercanas a la cuenca y las que habitan en ella. Otro aspecto identificado fue el manejo forestal inadecuado y la gestión deficiente de los recursos hídricos, los cuales están siendo sobrexplotados. El principal eje de acción que se propone en este ámbito es la promoción de las buenas prácticas en cuestiones de ejecución de procesos humanos y en lo referente a la preservación de la integridad de la cuenca.

Palabras clave: cuenca mboi caé; incidencia ambiental; desarrollo humano. 


\title{
Protection and environmental critical points of the Mboi Caé basin, city of Encarnación, Paraguay
}

\begin{abstract}
The present study aimed to determine the critical points of environmental protection and preservation of the Mboi Caé basin, considering the human incidence that is currently developing around it. In the methodological approach of the research, three general dimensions of analysis were raised: state of the water and forest cover, the state of the forest and the human factor. For data collection, the following instruments were used: mapping, observation and transect, photographic record, interviews, focus group with involved institutions, and documentary analysis. It was possible to verify the existence of inappropriate and uncontrolled land use in the referred basin, which is affecting the integrity of this and the basin in general, not to mention the negative effects that this factor exerts on the populations near the basin and the that inhabit it. Another aspect identified was inadequate forest management and deficient management of water resources, which are being over-exploited. The main line of action proposed in this area is the promotion of good practices in matters of human process execution and with regard to the preservation of the integrity of the basin.
\end{abstract}

Keywords: mboi caé basin; environmental incidence; human development.

Artículo recibido: 30 noviembre. 2021

Aceptado para publicación: 29 diciembre 2021 Correspondencia: jevelazquez@ derecho.uni.edu.py

Conflictos de Interés: Ninguna que declarar 


\section{INTRODUCCIÓN}

En la actualidad, cada vez se ha hecho más inminente y necesario el enfrentamiento de manera oportuna y eficaz del impacto ambiental generado por algunos factores relacionados con la acción humana, los cuales pueden causar el deterioro consecuente del entorno y el agotamiento de la base natural de algunas regiones y localidades por las demandas básicas relacionadas con la reproducción y el crecimiento de las poblaciones (Valadéz y Landa, 2003; Quintero, 2007) Algunos factores de riesgo identificable que han incidido en el deterioro ambiental a nivel mundial son el aumento de las emisiones de gases de efecto invernadero, la sobreexplotación de recursos naturales no renovables, la concentración de poblaciones en zonas específicas, la reducción de las reservas alimenticias, el desequilibrio en el crecimiento demográfico, el cambio climático, la modificación de los entornos naturales, entre otros aspectos (Valadéz y Landa, 2003; Balmaseda y García, 2013).

El enfrentamiento oportuno de riesgos ambientales al cual se hace referencia se ha enmarcado en el accionar los diferentes entes competentes a nivel internacional, los cuales han buscado evaluar y caracterizar los riesgos inminentes que enfrentan diferentes entornos naturales por la incidencia antrópica y los efectos adversos de la misma (Muñoz, 2011; Quintero, 2007; Carrasquilla, 2019). La identificación de riesgos ambientales potenciales es un punto de partida para la definición de políticas públicas dirigidas a la mitigación, manejo y control de los problemas ambientales, las cuales representan por su parte el interés que tienen los Estados por atender y mejorar las condiciones ambientales y favorecer el desarrollo sustentable (Muñoz, 2001; Wilk, Pineda y Moyer, 2006; Franquis e Infante, 2003).

La República de Paraguay cuenta con tres sistemas de agua natural muy importantes que contribuyen con el desarrollo social y económico de la región. De los tres sistemas de agua, dos tienen demarcación limítrofe con otros países de la región, estos son: Misiones e Yrenda. Misiones, es componente del Gran Sistema acuífero Guaraní, compartido con Brasil, Argentina y Uruguay. Mientras Yrendá, en el Chaco Central, es componente del Gran Chaco Americano, compartido con Bolivia y Argentina. Este último, también ha sido denominado Acuífero Toba (Matus y Dubarry, s/f)

Uno de estos sistemas acuíferos se ubica en la ciudad de Encarnación, la cual, se encuentra a las orillas del río Paraná. Actualmente, es la capital del departamento de Itapúa y cuenta 
con unos 118.300 habitantes. Recientemente ha alcanzado el nivel de ciudad sociourbana. Fue fundada en el año de 1615 por españoles y se consolidó como un asentamiento mercantil de fuerte actividad portuaria por su acceso al mar, siendo además una localidad en la que convergían las vías del ferrocarril que unían la ciudad de Asunción con Buenos Aires (Brites, 2016).

La ciudad, ha sido la receptora de un variado grupo de individuos, procedentes de distintas regiones, y ello ha permitido el enriquecimiento multicultural de la localidad. Tal condición no sólo se ha visto reflejada en sus costumbres, sino que formaba parte de la dinámica del centro urbano de la ciudad. Debido a estas colonias de inmigrantes, todavía se le conoce como "la perla del sur" (Brites, 2016). Así, el predominio de comerciantes extranjeros de diversos orígenes determinó, en un principio, el predominio de comercios en esta zona, junto con conjuntos residenciales que hoy han sido relocalizados.

En el año 2009 el distrito de Encarnación sufrió una serie de transformaciones, todo ello como resultado de un conjunto de obras en la Represa de Yacyretá. Esta represa, ubicada entre las Repúblicas de Paraguay y Argentina, en el río Paraná, tiene por finalidad convertir la energía hídrica en energía eléctrica. Se encuentra conformada por un conjunto de embalses de agua, lo que la convierte en uno de los principales sistemas de generación eléctrica del país. Muchos de sus sub embalses fueron construidos de manera artificial y los mismos tienen los siguientes nombres: Represa de Cierre del Brazo Aña-Cuá, Represa Principal Izquierda, Represa Lateral Izquierda, Represa Isla Yacyretá, Represa Lateral Derecha y Represa de Cierre del Brazo Principal (Brites, 2016).

Sin embargo, para construir muchas de las represas se procedió a inundar parte de la zona, acabando con biomas, especies y pueblos. La desaparición de especies endémicas, el desplazamiento de los pobladores y el exacerbado aumento de la inversión de ambos países (Paraguay y Argentina) derivó en constantes críticas y denuncias de corrupción. Así, los cambios, no sólo se hicieron sentir en el ámbito geográfico, sino que de igual manera, repercutieron a nivel ambiental, sociocultural, político, legal y económico.

Una de las grandes transformaciones fue la elevación del nivel de cota del embalse sobre el río Paraná, desde 76 a 83 metros sobre el nivel del mar (m.s.n.m). Esto inundó amplias zonas de la ciudad y otras áreas tradicionales, como la Villa Baja. El área formaba parte de la zona portuaria más tradicional y era considerada un patrimonio local, por lo que 
estaba vinculada a la identidad local y cultural. Todo ello, con la intención de hacer más amplia la represa (Brites, 2016).

Los paisajes costeros han sido alterados en la ciudad de Encarnación con las inundaciones que se han realizado para ampliar la cuenca. En el caso de los asentamientos poblacionales anteriores a la ejecución de obras, se ha debido relocalizar a los habitantes y se han tenido que redefinir las zonas limítrofes de la región. En consecuencia, la estructura física de la urbe ha sufrido cambios sustanciales; pero, además, ha debido orientarse hacia una nueva concepción de la ciudad y los servicios, especialmente, los relacionados con el turismo.

Como consecuencia de la incidencia humana mencionada más arriba y de todos los cambios territoriales que se han llevado a cabo en la demarcación limítrofe de la cuenca Mboi Caé, se ha constatado diferentes espacios afectados por fenómenos ambientales que ameritan ser caracterizados e identificados para lograr ejercer o llevar a cabo acciones futuras que promuevan su mitigación. Entre algunas afecciones que se han identificado, se tienen la existencia de erosión hídrica en toda la superficie del terreno, predominio de siembra tradicional sustentada en cultivo directo, falta de vegetación boscosa en algunos espacios de la cuenca, difícil determinación de la franja boscosa de la cuenca, entre otros aspectos. En este sentido, el presente estudio tiene como objetivo general determinar los puntos críticos de protección y preservación ambiental de la cuenca Mboi Caé, considerando la incidencia humana desarrollada en la actualidad alrededor de la misma.

\section{ESTRATEGIAS METODOLÓGICAS O MATERIALES Y MÉTODOS}

\subsection{Enfoque de la investigación}

El enfoque utilizado fue cuali y cuantitativos, en donde ambos se complementaron, utilizando, por lo tanto, un enfoque Mixto; teniendo en cuenta que el mismo implica un trabajo único y un diseño propio (Hernández, et. al., 2010).

\subsection{Diseño de la Investigación}

El diseño utilizado fue el DITRIAC (Diseño de triangulación concurrente), ya que fueron aplicados ambos métodos de manera simultánea, los datos cualitativos y cuantitativos fueron recolectados y analizados prácticamente en paralelo (Hernández, et. al., 2010).

\subsection{Tipo de investigación}

La investigación realizada fue de tipo Proyectivo, ya que la misma fue diseñada y preparada con las técnicas y procedimientos para el tipo de investigación seleccionado. El resultado de esta fase se expresa en los criterios metodológicos (Hurtado, 2010). 


\subsection{Muestra}

Para la presente investigación se tomaron como objeto de estudio las siguientes subcuencas: las subcuencas integrantes del arroyo Mboi Caé son las siguientes: Arroyo Potiy, Arroyo Curi y, Arroyo Maestra, Arroyo Porá, Arroyo Ita'angu'a, Arroyo Mboi Caé.

\subsection{Definición Operacional de las Variables}

En la

Tabla 1. Definición operacional de variables

\begin{tabular}{|c|c|c|c|}
\hline VARIABLES & DIMENSIONES & INDICADORES & INSTRUMENTO \\
\hline \multirow{3}{*}{$\begin{array}{c}\text { Estado } \\
\text { ambiental de la } \\
\text { cuenca del } \\
\text { Mboicae }\end{array}$} & $\begin{array}{l}\text { Estado del agua } \\
\text { Cobertura boscosa }\end{array}$ & $\begin{array}{l}\text { Calidad } \\
\text { Cantidad } \\
\text { Uso }\end{array}$ & Mapas temáticos \\
\hline & Estado del Bosque & $\begin{array}{l}\text { Ecosistema } \\
\text { Cobertura } \\
\text { Tipo de bosque } \\
\text { Fragmentación } \\
\text { Continuidad } \\
\text { Anchura } \\
\text { Densidad }\end{array}$ & $\begin{array}{l}\text { Imágenes } \\
\text { satelitales }\end{array}$ \\
\hline & Humana & $\begin{array}{l}\text { (balneario, puentes, } \\
\text { líneas de trasmisión } \\
\text { comunidades } \\
\text { indígenas, } \\
\text { asentamientos } \\
\text { humanos etc) } \\
\text { Ecosistema } \\
\text { modificado }\end{array}$ & $\begin{array}{l}\text { Observación } \\
\text { entrevistas }\end{array}$ \\
\hline
\end{tabular}

Aspectos políticos: Falta de presupuesto, falta de políticas. Falta de acción interinstitucional, falta de claridad en la normativa, capacidad institucional

Aspectos técnicos: fragmentación del bosque, intervenciones constantes, anchura no adecuada para el cauce

Fuente: Elaboración Propia

presentada a continuación se muestra la definición operacional de variables propuestas para el estudio:

Tabla 1. Definición operacional de variables

\begin{tabular}{clll|l} 
VARIABLES & DIMENSIONES & INDICADORES & INSTRUMENTO \\
\hline $\begin{array}{c}\text { Estado } \\
\text { ambiental de la }\end{array}$ & $\begin{array}{l}\text { Estado del agua } \\
\text { Cobertura boscosa }\end{array}$ & $\begin{array}{l}\text { Calidad } \\
\text { Cantidad } \\
\text { Uso }\end{array}$ & Mapas temáticos \\
\hline
\end{tabular}




\begin{tabular}{l|l|l|l}
\hline $\begin{array}{l}\text { cuenca del } \\
\text { Mboicae }\end{array}$ & $\begin{array}{l}\text { Ecosistema } \\
\text { Cobertura } \\
\text { Tipo de bosque } \\
\text { Fragmentación } \\
\text { Continuidad } \\
\text { Anchura } \\
\text { Densidad }\end{array}$ & $\begin{array}{l}\text { Imágenes } \\
\text { satelitales }\end{array}$ \\
& Estado del Bosque & $\begin{array}{l}\text { (balneario, puentes, } \\
\text { líneas de trasmisión } \\
\text { comunidades } \\
\text { indígenas, } \\
\text { asentamientos } \\
\text { humanos etc) } \\
\text { Ecosistema } \\
\text { modificado }\end{array}$ & Observación \\
& Humana & \\
\hline
\end{tabular}

Aspectos políticos: Falta de presupuesto, falta de políticas. Falta de acción interinstitucional, falta de claridad en la normativa, capacidad institucional Aspectos técnicos: fragmentación del bosque, intervenciones constantes, anchura no adecuada para el cauce

\section{Fuente: Elaboración Propia}

\subsection{Instrumentos y técnicas de recolección de datos}

Básicamente, fueron empleadas las siguientes herramientas para la resolución del objetivo planteado:

- Mapeo, observación y transecta, registro fotográfico, entrevistas

- Grupo Focal Instituciones involucradas. Actores Institucionales: Gobernación de Itapúa, Municipalidad de Encarnación, INFONA, MADES, la herramienta del grupo focal usada fue el análisis FODA (Fortalezas, Oportunidades, Debilidades y Amenazas).

- Análisis documental, Método Delphi (Docentes Universitarios, Ingenieros Forestales, Ex ministros del Ambiente, Investigadores, Ong, EBY, ITAIPU)

\subsection{Procedimiento y aplicación de instrumento}

Para determinar las franjas de protección boscosa de los cauces hídricos se utilizaron imágenes satelitales que cubrieron el área de interés (Distrito de Encarnación) las LANDSAT 5 sensor TM (Tematic Maper) que estuvieron compuestas por 7 u 8 bandas espectrales, que fueron elegidas, especialmente, para el monitoreo de la vegetación, para aplicaciones geológicas y para el estudio de los recursos naturales. Las mismas, cumplen con el requisito del $0 \%$ de nubes sobre el área de estudio. La estación del año para las 
imágenes es el invierno (por la mayor facilidad de distinción de tipos de coberturas de suelo).

Los datos de campo fueron tomados in situ en el área correspondiente de uso del suelo cartografiados según las imágenes satelitales. Las áreas fueron georeferenciadas con GPS (Sistema de posicionamiento global) y cámara fotográfica.

Mapas temáticos: Las informaciones obtenidas en el procesamiento de los datos de las imágenes satelitales, se utilizarán como base para la elaboración de mapas temáticos de cobertura boscosa y franjas de protección de los cauces hídricos de la ciudad de Encarnación.

Una vez definida la situación actual de la cobertura boscosa de los cauces hídricos de la ciudad de Encarnación, se realizó un análisis FODA sobre ellos, de manera a identificar los puntos críticos que deberían ser observados en un posterior diseño de lineamientos sobre recomposición, restauración, manejo de riesgos, ODS, Paraguay 2030, PAN, PFN.

\section{RESULTADOS Y DISCUSIÓN}

El mapeo realizado durante el estudio permitió, en primer lugar, determinar que la Cuenca Mboi Caé cubre un territorio total de 348 km2. De igual manera, se determinó que forma parte de los distritos Cambyretá, Nueva Alborada, Capitán Miranda, Encarnación, San Juan del Paraná, Jesús, La Paz y Fram en el Departamento de Itapúa, siendo su capacidad de captación de agua de 64.000 hectáreas constituyendo, una de las cuencas más importantes para el embalse de Yacyretá. Con respecto al área geográfica se determinó que la cuenca está constituida por un sistema de lomas y lomadas altas y bajas cuyo relieve se caracteriza por presentar una forma ondulada cercana a los principales cursos de agua y afluentes.

La revisión de mapas y relieve permitió identificar una zona de pendientes entre el 6,0 y $7,0 \%$ y una ligera ondulación en las zonas altas y lomadas. De las imágenes satelitales, el mapeo y la observación también se apreció que sus suelos poseen cualidades óptimas para la agricultura y actividades forestales, ya que la mayoría de ellos son suelos de tipo arcilloso y de rocas basálticas. Desde el punto geomorfológico, se destacaron dos tipos de zonas en el área, de modo que se estableció que en la zona alta el área es homogénea, mientras que en las pendientes es irregular. Presentan una topografía accidentada convexa (altas y lomadas), plana (cimas y topos) y mixta en las zonas más accidentadas. Estos resultados hicieron posible la clasificación de cada uno de los suelos según su capacidad 
de uso. Los suelos de las zonas altas y de la topografía casi planas son de tipo II. Su principal limitación radica en su bajo contenido de fósforo y en un alto riesgo hídrico.

En lo referente al estudio de los suelos, se comprobó que la cuenca Mboi Caé presenta características propias y específicas en cada una de sus zonas, delimitadas, atribuidas o clasificadas según diferentes tipos de suelos. Sobre este particular, se identificaron y clasificaron los suelos en función de su capacidad de uso. Se observó que los suelos con problemas de pendiente y menor profundidad efectiva fueron incluidos en la clase III. Estos suelos presentan un alto riesgo hídrico por su pendiente pronunciada, topografía accidentada y su bajo contenido de fósforo.

Las áreas con problemas topográficos de pendientes pronunciadas forman parte de la clase IV. Este tipo de suelos está destinado al sector agropecuario, pero también pudieran ser destinados para el rubro agrícola. Los suelos de las zonas más bajas de la cuenca están ubicados dentro de la clase V y se caracterizan por el exceso de agua que los hace aptos sólo para actividades pecuarias, áreas de protección o de reserva. Por último, los suelos con problemas topográficos, de pendientes muy pronunciadas y de baja profundidad efectiva, se incluyeron en el perfil VI, cuya cualidad destaca para la actividad ganadera. A modo de síntesis, se resumen en la siguiente tabla los tipos de suelos según su capacidad de uso y características:

Tabla 2. Tipos de suelo según capacidad y características

\begin{tabular}{c|l}
$\begin{array}{c}\text { Tipo de suelo } \\
\text { según capacidad } \\
\text { de uso }\end{array}$ & $\begin{array}{l}\text { Características } \\
\text { Suelos de las zonas más altas y de topografía casi plana. Presenta } \\
\text { como limitaciones básicas el bajo contenido de fósforo asimilable } \\
\text { y un ligero riesgo a la erosión hídrica. Se recomiendan adoptar } \\
\text { prácticas sencillas de manejo de suelo, las cuales incluyen la } \\
\text { adopción del sistema de siembra directa, la incorporación de } \\
\text { abono orgánico utilizando abonos verdes o cascarilla de algodón } \\
\text { o coco, tung u otro producto similar; rotación de cultivos, } \\
\text { incluyendo leguminosas en dicha práctica; y aplicación de } \\
\text { fertilizantes químicos que contenga los tres macronutrientes } \\
\text { primarios (N - P - K), en cantidad conforme al cultivo a ser } \\
\text { establecido. }\end{array}$ \\
\hline Suelo tipo III & $\begin{array}{l}\text { Áreas con problema de pendiente y menor profundidad efectiva. } \\
\text { Presentan como limitaciones básicas el alto riesgo a la erosión } \\
\text { hídrica, como consecuencia de la pendiente pronunciada, }\end{array}$ \\
\hline
\end{tabular}


topografía accidentada, asociada a la alta erosividad de la lluvia del área, que oscila entre 1.750 a $1.800 \mathrm{~mm}$ anual; y bajo contenido de fósforo asimilable. Se recomienda implantar prácticas intensivas de manejo de suelo, principalmente el control de la erosión hídrica. Las practicas que se recomiendan son la implantación de cultivos en terrazas, combinándolas con otras prácticas, tales como siembra directa o labranza mínima, implantación de cultivos de coberturas y en contornos; rotación de cultivos.

\begin{tabular}{|c|c|}
\hline Suelo tipo IV & $\begin{array}{l}\text { Áreas con problemas topográficos y de pendiente pronunciada. } \\
\text { Tienen aptitud preferentemente ganadera, pudiendo sin embargo } \\
\text { utilizar también con rubros agrícolas, pero con adopción de } \\
\text { prácticas intensivas y complejas de manejo de suelo, como ser la } \\
\text { implantación de terrazas, combinados con cultivos de cobertura, } \\
\text { siembra directa o labranza mínima, un buen programa de } \\
\text { fertilización, control de la reacción y de la erosión hídrica del } \\
\text { suelo }\end{array}$ \\
\hline Suelo tipo V & $\begin{array}{l}\text { Suelos de las zonas más bajas. Su limitación principal es el } \\
\text { exceso de agua en el perfil por largos periodos de tiempo durante } \\
\text { el año, lo que restringe su aptitud de uso para explotación } \\
\text { pecuaria. }\end{array}$ \\
\hline Suelo tipo VI & $\begin{array}{l}\text { Zonas con problemas topográficos, de pendiente muy } \\
\text { pronunciada y fundamentalmente con baja profundidad efectiva, } \\
\text { pedregoso dentro del perfil y en forma localizada en superficie. } \\
\text { Tienen aptitud preferentemente ganadera, recomendándose } \\
\text { aprovechar, si es posible, la vegetación natural, o implantar } \\
\text { pastos de mucha cobertura. }\end{array}$ \\
\hline
\end{tabular}

Fuente: Global Consultores (2016)

Asimismo, se constató la presencia de erosión hídrica en toda la superficie del territorio, ubicándose la presencia de costras superficiales en terrenos planos, mientras que, en terrenos más aplanados se encuentran arrastres laminares o en surcos superficiales. En zonas con una inclinación más pronunciada, surcos profundos o zanjas, se advierte el predominio de la siembra tradicional sustentada en el cultivo directo que, si bien es una forma de contener la erosión hídrica de los suelos, hacen falta más esfuerzos para detener este fenómeno. Esta cuenca presenta un curso de agua permanente o intermitente y no tiene la vegetación boscosa necesaria para protegerse de la contaminación física arrastrada por las masas de agua que corren rápidamente y con fuerza. Sin embargo, se aprecia la existencia de gramíneas que cumplen la función de filtrar los agentes contaminantes (sedimentos) antes de llegar al cauce.

En la parte alta de la cuenca Mboi Caé, el curso de agua se muestra desnuda en su ribera y se debe a que esta parte es más accidentada y la erosión es más acentuada, ya que se 
observa la existencia de deforestación en las orillas de esta. Igualmente, se encontraron espacios topográficos accidentados, específicamente, al borde de las lomadas predominando suelos rasos y pedregosos, esto trae consigo un alto riesgo de erosión hídrica. Además, también se pudo constatar que cada vez se torna más difícil establecer la franja boscosa de la cuenca Mboi Caé, puesto que se advierte el incremento acelerado de la población urbana generando la necesidad de buscar más espacios para el asentamiento de los pobladores y, existe, a su vez, una carencia de planes de ordenamiento de las zonas urbanas. Esto lleva a suponer la falta de seguimiento por parte de las instituciones gubernamentales y municipales en torno a este tema, puesto que, a medida que se genere un incremento en la población, se requiere más uso de los suelos y de los recursos hídricos.

Por otro lado, se logró establecer que la cuenca Mboi Caé tiene un área aproximada de $348 \mathrm{~km}^{2}$ y una pendiente en promedio del $8 \%$ y $24.3 \mathrm{~km}^{2}$ de área crítica relacionada con el manejo del suelo, recursos hídricos y deforestación que afectan la calidad de vida de los residentes de la población y las actividades de producción de esta. No obstante, el análisis de la información permitió verificar que tanto entes municipales como la comunidad en general (organizaciones locales, comités vecinales, productores locales y la sociedad civil) mostraron su disponibilidad para intervenir y apoyar iniciativas y actividades que promuevan la elaboración de propuestas de una mejor gestión de las cuencas y, al mismo tiempo, se constató que cuentan con medios de comunicación masivos (locales y regionales) que pudieran facilitar la transmisión de la información derivada de los estudios previamente realizados, facilitando la rápida y oportuna conexión entre la población.

Con respecto a las buenas prácticas relacionadas con el uso del suelo y los recursos hídricos, la información obtenida permitió precisar que la población intenta desarrollar buenas prácticas en algunos territorios de la cuenca Mboi Caé y se interesan por disminuir los daños ambientales en el suelo y el agua. Además, buscan reponer el daño de la tala con la reforestación de plantas nativas y de rápida evolución y crecimiento para equilibrar el ecosistema de la cuenca y así filtrar los agentes contaminantes que pudieran existir en el mismo. Por otro lado, se pudo apreciar que cada municipio conserva sus propios rasgos culturales y concepciones en el manejo de los suelos y el agua, lo cual, figura como una 
fortaleza en el marco de la elaboración de propuestas para mejorar la situación de la cuenca.

En este contexto, uno de los mapas temáticos elaborados fue sobre el uso de suelo en la región, presentándose el mismo a continuación:

Figura 1: Mapa de uso de suelo de la cuenca Mboi Caé

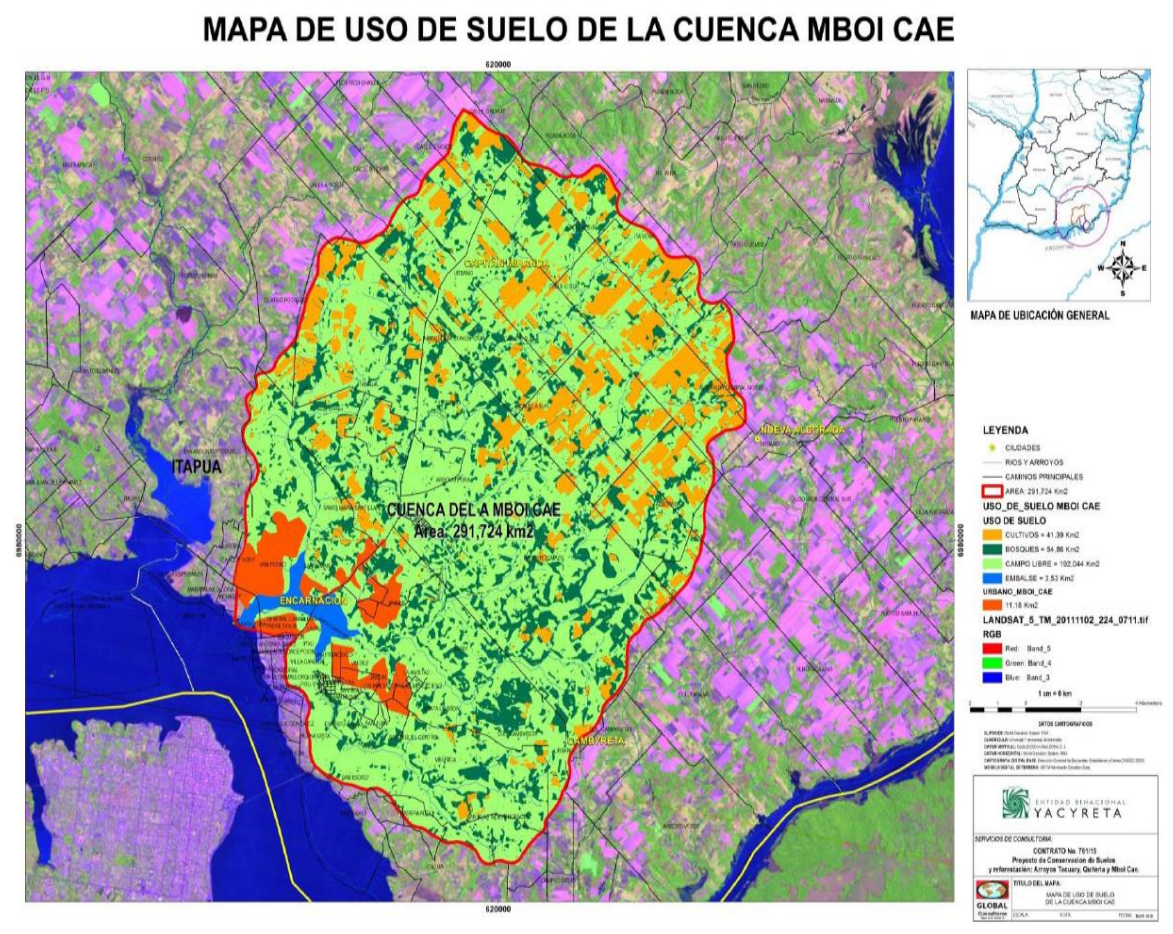

Este planteamiento pone de manifiesto que tanto la sociedad civil como los municipios tienen clara la importancia del uso de los suelos y los recursos hídricos y la necesidad de emprender gestiones que busquen disminuir el impacto de las acciones humanas en la cuenca Mboi Caé. De igual manera, también se pudo precisar que toda la gestión ambiental se enfrenta a desafíos demográficos presentes en el crecimiento de las zonas urbanas que cada vez se desarrollan más y revisten la necesidad de asegurar la calidad de vida de la población. Esto significa que, a mayor presencia de zonas urbanas, más impacto existe en el crecimiento de la actividad productiva, lo que obliga la creación de más servicios socio productivos y comerciales que asistan a la población, situación que se afianza por la ubicación geográfica de la cuenca, ya que esta tiene sus límites con otras zonas que propician el movimiento comercial y turístico de la misma.

Con respecto a la condición de los humedales, se constató que el llenado del embalse Yacyretá involucra una gran extensión de territorios secos originados con base a múltiples 
factores, contribuyendo a la creación de una nueva distribución territorial que incidió en la creación de nuevos espacios turísticos y la inversión por parte de agentes externos e internos para beneficio de la población. Se advierte que las leyes promueven orientaciones precisas sobre el resguardo de los humedales, ya que estos tienen la función de conservar la biodiversidad, la conservación y mantenimiento del paisaje de la cuenca.

En cuanto a las buenas prácticas, cabe igualmente señalar que existe una parte de la población agrícola que busca implementar técnicas que dejen atrás las prácticas negativas de siembra y producción de alimentos, sin embargo, sus esfuerzos no son suficientes, puesto que no se advierte la aplicación de conocimientos científicos que avalen la implementación de estas técnicas. Al mismo tiempo, se evidencia que entre los pobladores faltan conocimientos en el proceso de manipulación y conservación de productos químicos que pudieran provocar graves accidentes $\mathrm{y}$, posteriormente, daños al agua y el suelo de las cuencas.

De igual manera, se observó que los suelos presentan evidencia de erosión hídrica, lo que afecta su capacidad de uso y causa su degradación. Además, se evidenció la práctica de actividades que ponen en riesgo la calidad de los recursos existentes en la cuenca Mboi Caé, como son la quema de basura, ausencia de lugares para el almacenamiento de la misma y su correcta recolección en función de sus propiedades orgánicas, quema de pasturas, contaminación por productos químicos y otras señales que ponen en peligro la conservación y resguardo de los recursos de la zona.

En la cuenca Mboi Caé se apreciaron notorias diferencias con respecto a la ubicación espacial de las zonas urbanas y rurales, ya que se advierte que en las zonas metropolitanas de Encarnación la expansión hacia otras áreas limítrofes como un rasgo característico de su desarrollo urbano, otros sectores se encargan de mantener la producción agrícola con el cultivo de distintos rubros (soja, maíz, girasol) y actividades agropecuarias. Esta situación pone en evidencia la necesidad de plantearse estrategias que integren estos hechos mencionados, de manera que se consolide en un abordaje completo de todas las áreas y se obtengan beneficios sobre eso, porque en las zonas urbanas exigen el incremento de servicios de agua potable, aumentando su consumo, mientras que en las zonas rurales se ven disminuidos sus recursos hídricos, lo que dificulta la gestión de conservación de la biodiversidad de las cuencas. 
Cabe señalar que uno de los grandes riesgos ambientales presentes en la cuenca está relacionado con el uso del agua, más específicamente, con la erosión hídrica de los suelos. Este fenómeno de carácter natural y entrópico amerita un abordaje metodológico integral que identifique las causas, consecuencias y efectos sobre la calidad del agua. En este sentido, la erosión hídrica presente en los suelos de la cuenca tiene su origen en la deforestación indiscriminada, el uso y abuso de los suelos y la implementación inadecuada de tecnologías que impactan en la capacidad de uso de los suelos. Es por eso, que resulta imperativo asumir esta situación desde una perspectiva integral que lleve a comprender que los problemas del agua se derivan del uso de este recurso en el contexto de las tierras y el uso de todos los actores sociales. Por esa razón, es imprescindible partir de un diagnóstico exhaustivo para precisar líneas de acción eficientes que busquen disminuir los problemas ambientales que afectan al agua.

\section{CONCLUSIÓN O CONSIDERACIONES FINALES}

Como parte de las conclusiones encontradas en el marco del presente estudio, se puede considerar finalmente que:

Existe en la cuenca un uso del suelo inapropiado y no controlado que está afectando la integridad de este y de la cuenca en general, sin mencionar, además, otros efectos negativos que ejerce este factor sobre las poblaciones cercanas a la cuenca y las que habitan en ella.

Manejo forestal inadecuado y gestión deficiente de los recursos hídricos, los cuales están siendo sobrexplotados y están trayendo consecuencias negativas sobre la integridad y potencial uso futuro de los recursos presentes en la cuenca. El principal eje de acción que se propone en este ámbito es la promoción de las buenas prácticas en cuestiones de ejecución de procesos humanos, como en lo respectivo a la preservación de la integridad de la cuenca y aprovechamiento sustentable de los recursos.

La cuenca Mboi Caé ha sufrido muchos cambios en su estructura territorial, lo que hace que cada vez sea más difícil establecer los límites de la franja boscosa, puesto que esta cuenca es el centro de una creciente población urbana con situación de expansión constante. Precisamente, esto se configura como un factor negativo, ya que, en aras de expandir los alcances de la zona se generan situaciones en las que se requieren crear más y mejores servicios para cubrir las necesidades de la población, siendo el agua uno de los 
principales recursos demandados en la zona, por consiguiente, uno de los más afectados por el uso humano.

\section{LISTA DE REFERENCIAS}

Balmaseda, C. \& García, Y. (2013). Calidad de las aguas de la cuenca del río Naranjo, municipio Majibacoa, provincia Las Tunas para el riego. Cultivos Tropicales, 34(4), 68-73. Disponible en: http://scielo.sld.cu/scielo.php?script=sci_arttext\&pid=S025859362013000400011. Consultado el: 26 de diciembre del 2021.

Brites, W. (2016). La ciudad de encarnación, Paraguay. Intervención urbana a gran escala y nuevos procesos socio-espaciales. Revista Latinoamericana de Comunicación, $\mathrm{N}^{\circ} 130$, diciembre 2015-marzo 2016, pp. 33-52. Disponible en: https://revistachasqui.org/index.php/chasqui/article/view/2510. Consultado el: 10 enero 2021.

Carrasquilla, O. (2019). Bosques para el agua. Integración del manejo forestal sostenible y el manejo de recursos hídricos. Caracas: CAF. Disponible en: http://scioteca.caf.com/handle/123456789/1493.

Franquis, F. e Infante, A. (2003). Los bosques y su importancia para el suministro de servicios ambientales. Revista Saber ULA, núm. 4, vol. I. pp. 1-12. Disponible en: http://www.saber.ula.ve/bitstream/123456789/24124/2/articulo2.pdf. Consultado el: 26 de diciembre del 2021.

Global Consultores. (2016). Proyecto de Conservación de Suelos y Reforestación en la Cuenca de los Arroyos Tacuary, Mbói Cae y Quiteria, Itapúa. Primera Parte: Bases para un Plan de Gestión de la Erosión Hídrica de Cuencas. Asunción: Entidad Binacional Yacyretá.

Hamilton, L. (2009). Los bosques y el agua. Estudio temático elaborado en el ámbito de la Evaluación de los recursos forestales mundiales. FAO. Disponible en: http://www.fao.org/3/i0410s/i0410s00.htm. Consultado el: 26 de diciembre del 2021.

Hernández, R.; Fernández, C. y Baptista, C. (2010). Metodología de la investigación. México: Mc Graw Hill.

Hurtado, J. (2010). Guía para la comprensión holística de la ciencia. Caracas: Sypal. 
Matus y Dubarry. (s/f). Delimitación de cuencas hidrográficas, departamento de Itapuá y Alto Paraná, Paraguay (escala 1:25.000). Paraguay: Matus \& Dubarry, Consultora Ambiental.

Muñoz, G. (2011). Análisis de la política ambiental colombiana en la década 2000-2010. Revista Semestre Económico, volumen 14, No. 30, pp. 121-134. Disponible en: http://www.scielo.org.co/pdf/seec/v14n30/v14n30a7.pdf. Consultado el: 28 noviembre 2021.

Porras, I. (2003). Valorando los Servicios Ambientales de Protección de Cuencas. Tercer Congreso Latinoamericano de Protección de Cuencas en Arequipa Chile del 9 al 13 de junio de 2003. 15 p. Disponible en: https://www.researchgate.net/profile/Ina_Porras/publication/228538718_Valora ndo_los_servicios_ambientales_de_proteccion_de_cuencas_consideraciones_me todologicas/links/0c9605239c513d13ec000000.pdf

Quintero, G. (2007). Políticas públicas y el medio ambiente. Revista Tecnología en Marcha, volumen 21-1, enero-marzo 2008, pp. 141-151. Disponible en: https://dialnet.unirioja.es/descarga/articulo/4835691.pdf. Consultado el: 28 noviembre 2021.

Secretaria del Convenio sobre la Diversidad Biológica. (2009). Gestión forestal sostenible, biodiversidad y medios de vida: Guía de buenas prácticas. [En línea]. Disponible en: https://es.scribd.com/presentation/464449250/cdb-guide-desbonnes-practiques-forets-ppt-es

Valadéz, A. y Landa, P. (2003). Política de gestión ambiental. Características y lineamientos generales. Revista Psicología y Ciencia Social, N², volumen 5, pp. 54-61. Disponible en: https://www.redalyc.org/pdf/314/31405205.pdf. Consultado el: 28 noviembre 2021.

Wilk, D.; Pineda, C.; Moyer; D. (2006). Lineamientos estratégicos para la gestión ambiental urbana en Centroamérica. Serie de Estudios Económicos y Sectoriales, volumen 1 , pp.1-61. Disponible en: https://www.researchgate.net/publication/254422101_Lineamientos_estrategicos _para_la_gestion_ambiental_urbana_en_Centroamerica. Consultado el: 28 noviembre 2021. 